\title{
CORRECTION
}

\author{
Murat Kandaz - Hüsnü Dal
}

\section{Correction to: A comparative study of modified strain gradient theory and modified couple stress theory for gold microbeams}

Published online: 25 July 2019

(c) Springer-Verlag GmbH Germany, part of Springer Nature 2019

\section{Correction to: Arch Appl Mech (2018) 88:2051-2070 \\ https://doi.org/10.1007/s00419-018-1436-0}

This is an erratum to the previously published version due to systematical errors in figures. Only the legends and axes names of the Figs. 1, 2, 3, 4, 5, 6, 7, 8, 9, 10, 11 and 12 have been changed.

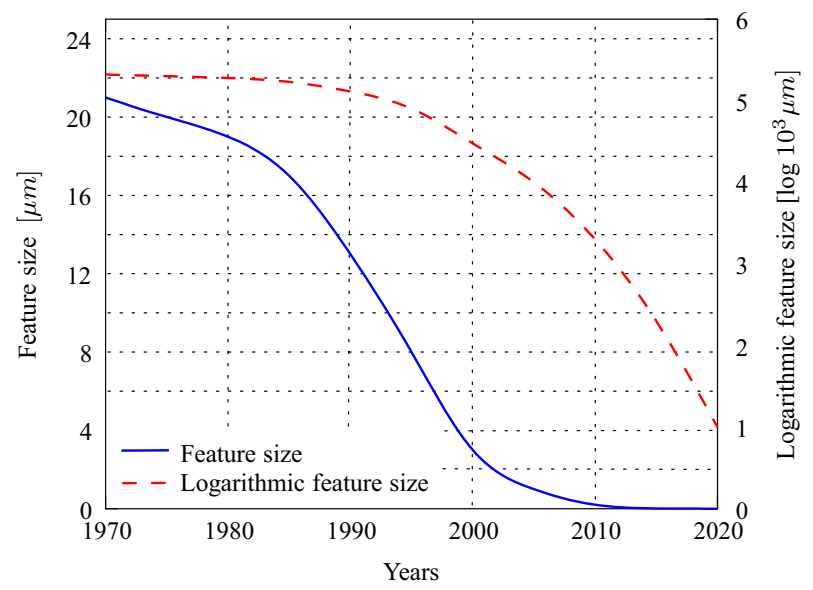

Fig. 1 Feature sizes of MEMS and NEMS with years

The original article can be found online at https://doi.org/10.1007/s00419-018-1436-0

M. Kandaz $\cdot$ H. Dal $(\varangle)$

Department of Mechanical Engineering, Middle East Technical University, Dumlupınar Bulvarı 1, 06800 Ankara, Turkey

E-mail:dal@metu.edu.tr 


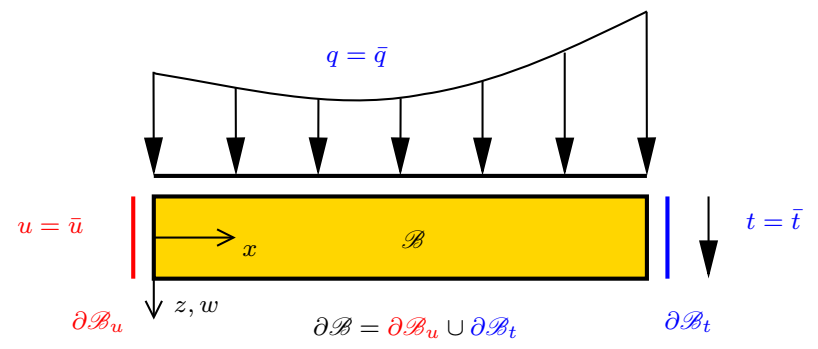

Fig. 2 A beam $\mathscr{B}$ with Dirichlet boundary conditions on $\partial \mathscr{B}_{u}$ and Neumann boundary conditions on $\partial \mathscr{B}_{t}$

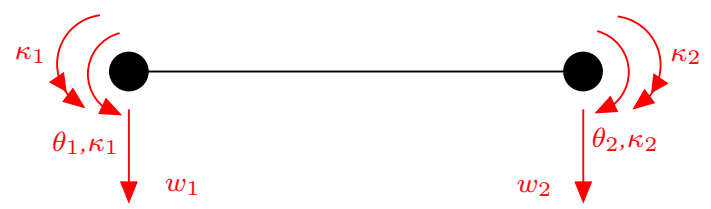

(a)

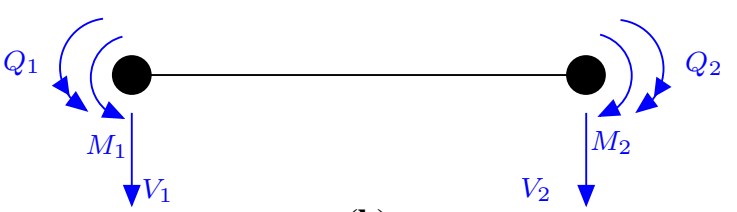

(b)

Fig. 3 Dirichlet and Neumann boundary conditions for a the Euler-Bernoulli beam based on the modified strain gradient theory

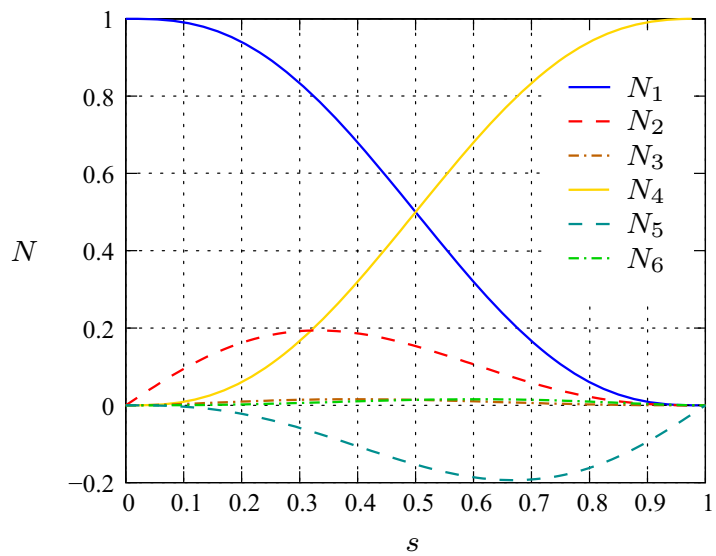

(a)

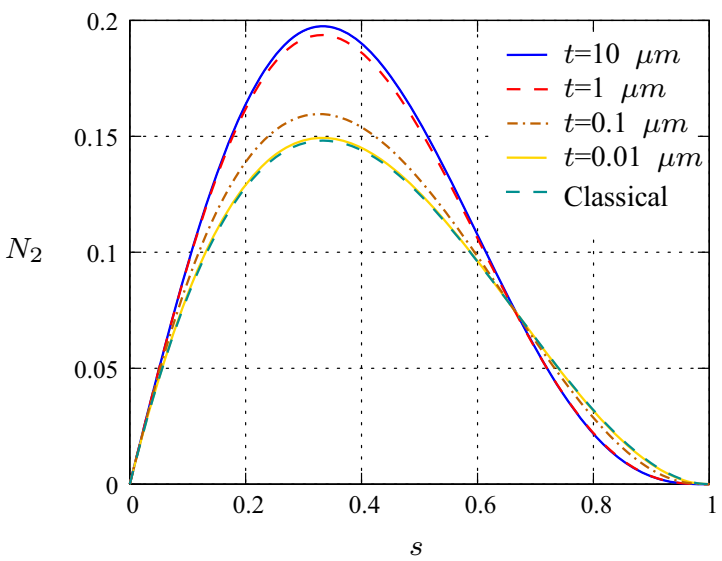

(c)

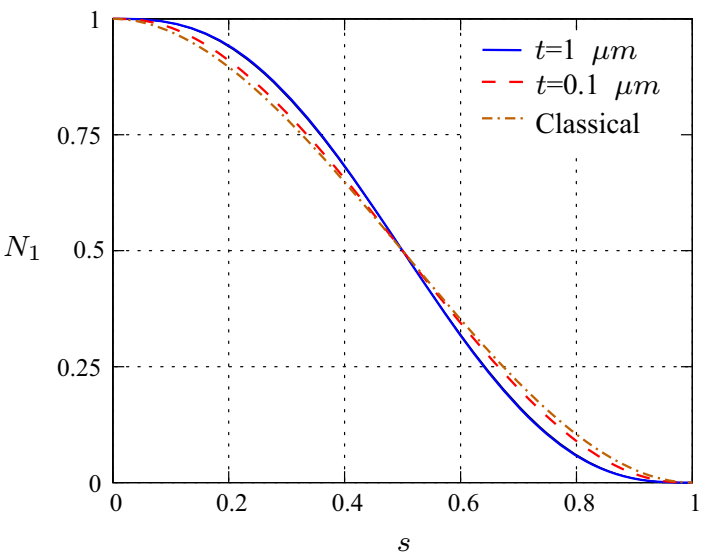

(b)

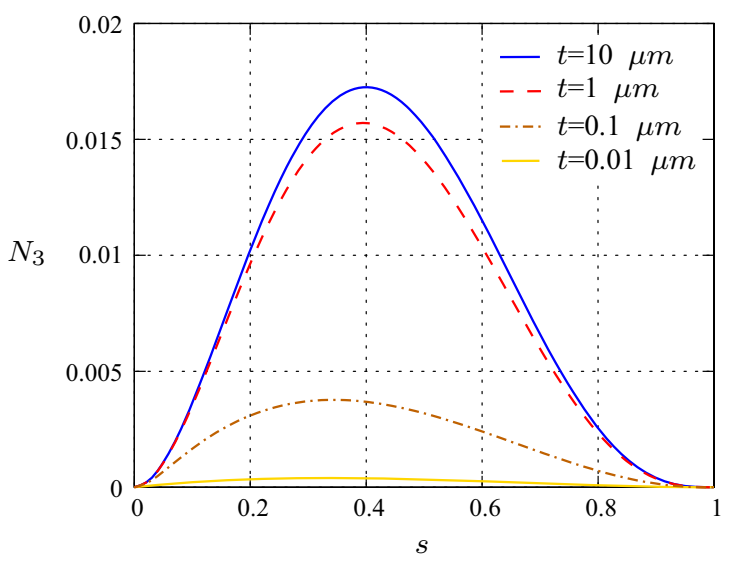

(d)

Fig. 4 Shape functions for MSGT: All elements of shape function matrix $N$ are given in a, whereas $N_{1}, N_{2}$, and $N_{3}$ are given in b-d, respectively, based on beam thickness. Note for $N_{1}$ and $N_{2}$, the curves do not change even if $t$ is increased more than those given as the upper bound in the figures. They also approach to classical Hermite cubic shape functions with decreasing values of 


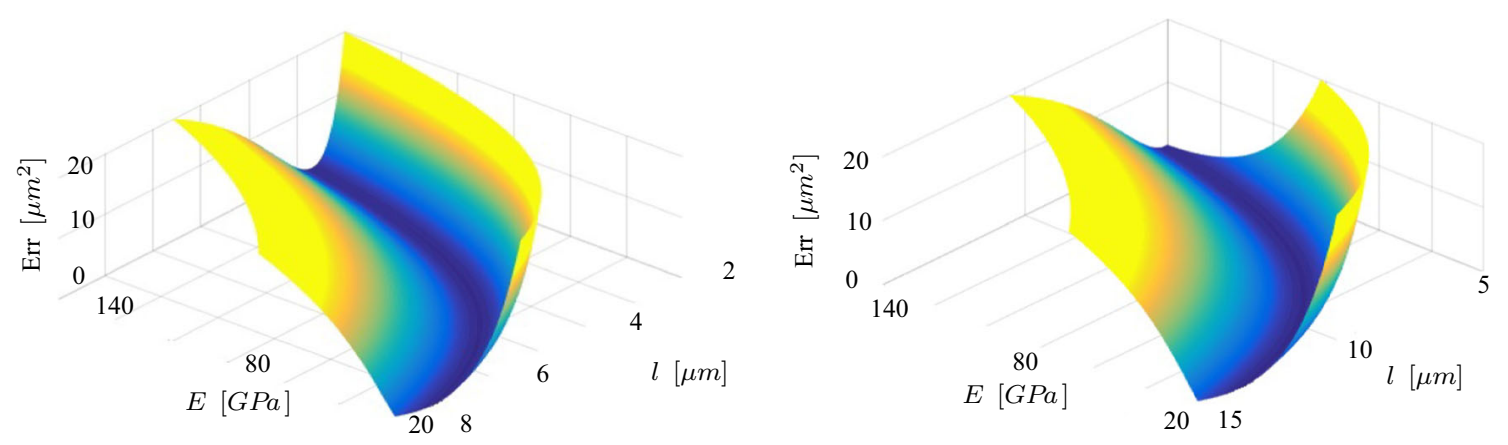

(a)

(b)

Fig. 5 Corresponding $E r r, E$, and $l$ values for a MSGT and $\mathbf{b}$ MCST

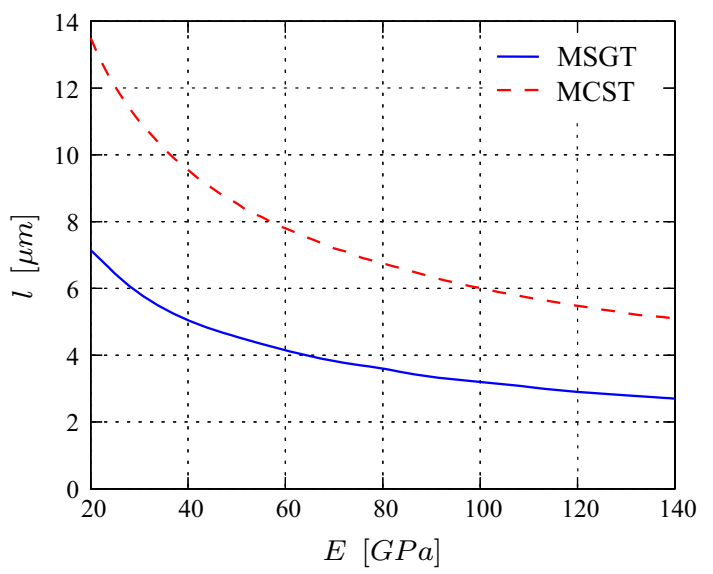

Fig. 6 Sets of values for length scale parameter $l$ with respect to varying Young's modulus $E$ obtained from minimum error expression Err
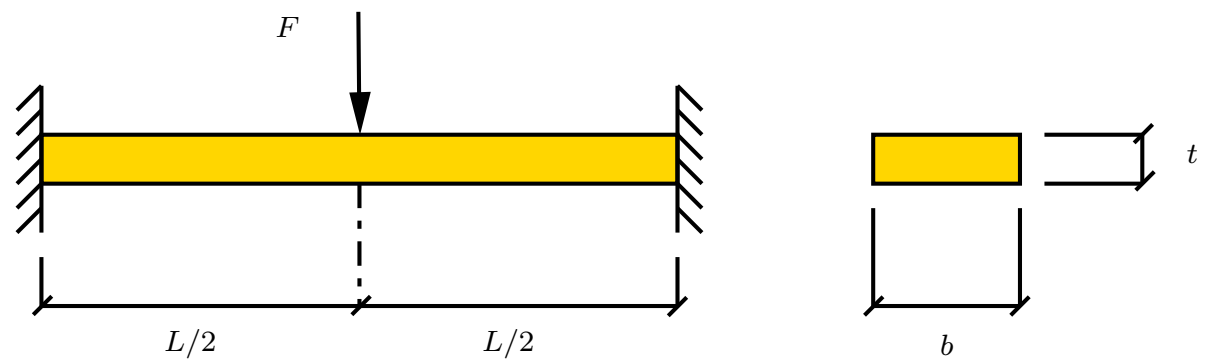

Fig. 7 The illustration of the geometry and the boundary conditions of the experiments [24]. The simulation is run with 10 identical beam elements 


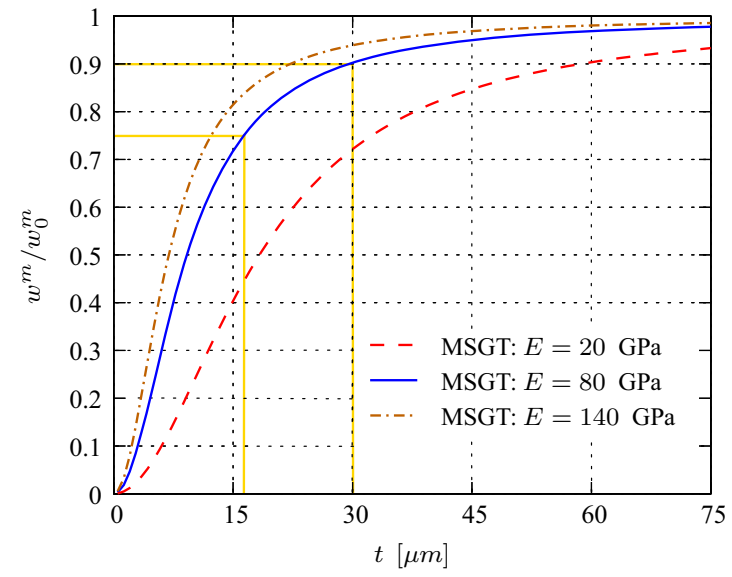

(a)

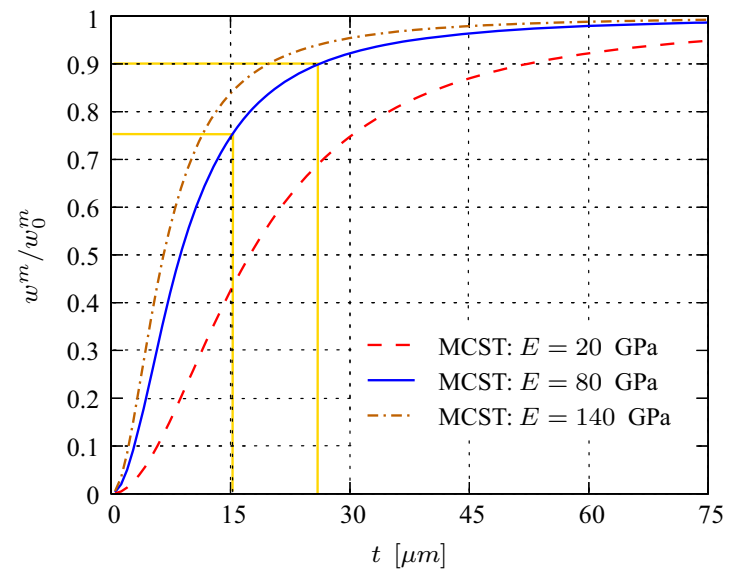

(b)

Fig. 8 Ratio of midpoint deflections predicted with higher-order theories to those predicted with classical theory $\left(w^{m} / w_{0}^{m}\right)$ for beams with constant aspect ratio of 1:5:20 for a MSGT and b MCST. $F=30 \mathrm{mN}$

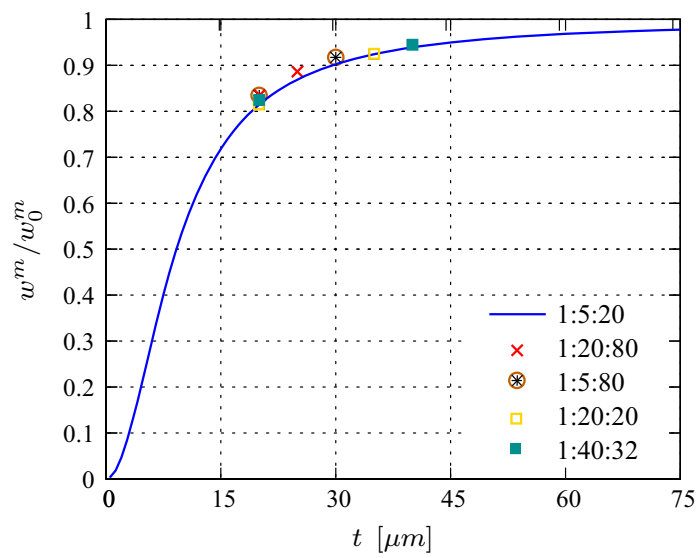

Fig. $9\left(w^{m} / w_{0}^{m}\right)$ for different aspect ratios for MSGT 


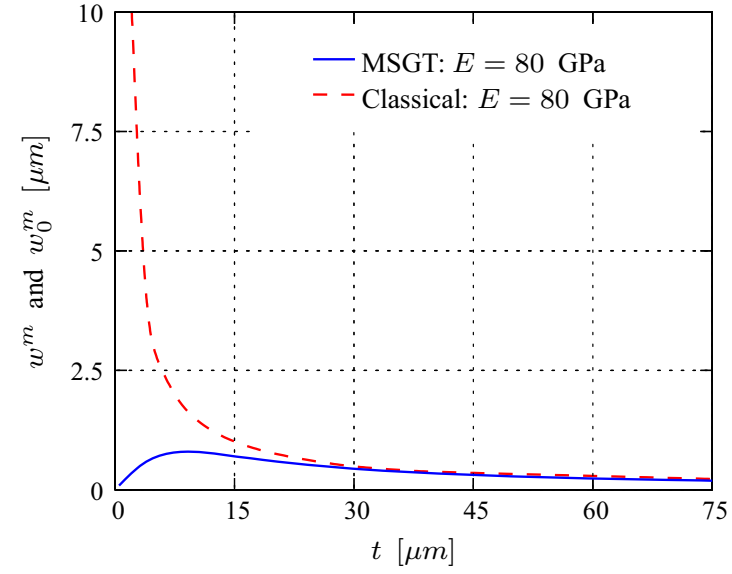

(a)

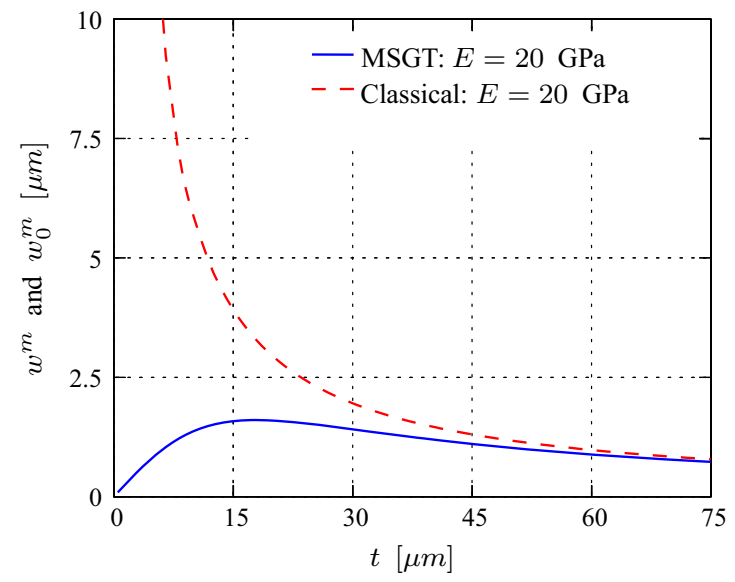

(c)

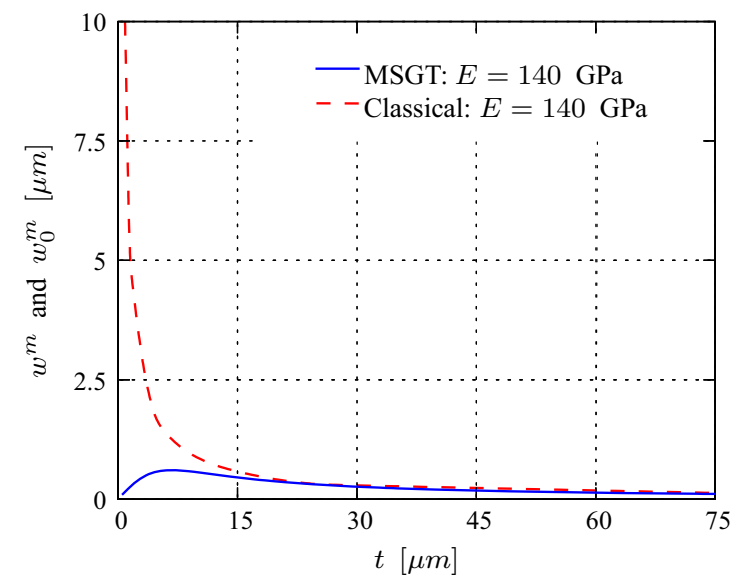

(e)

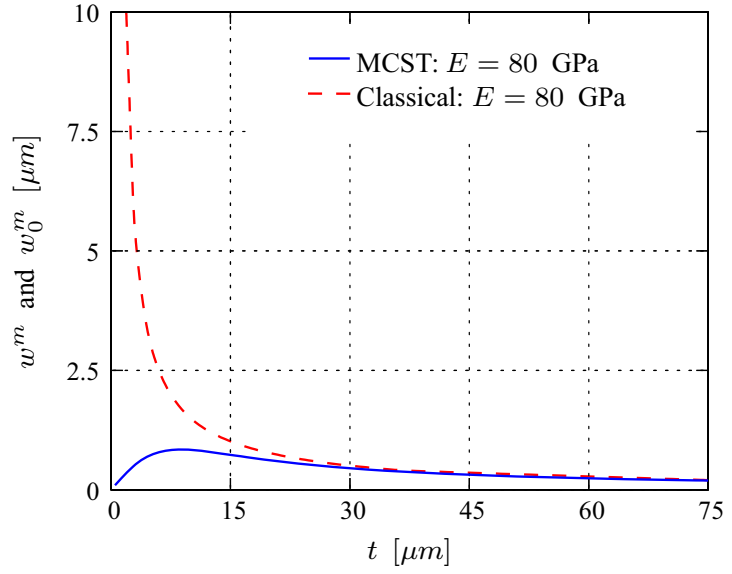

(b)

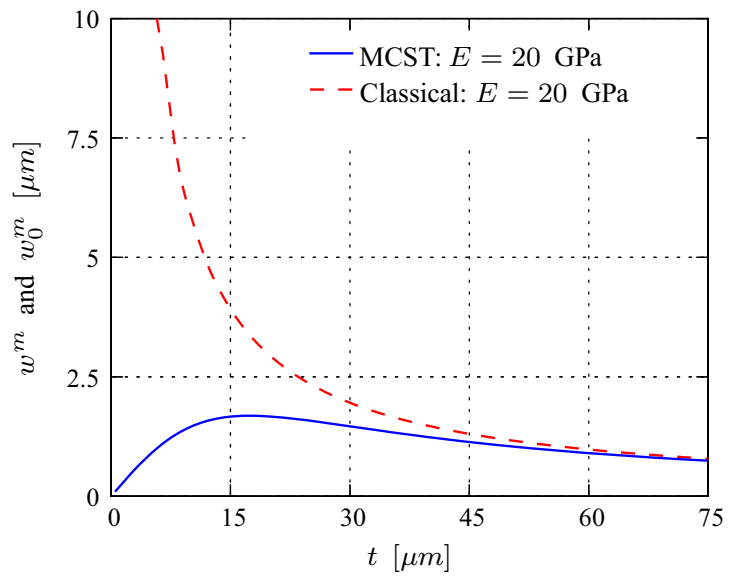

(d)

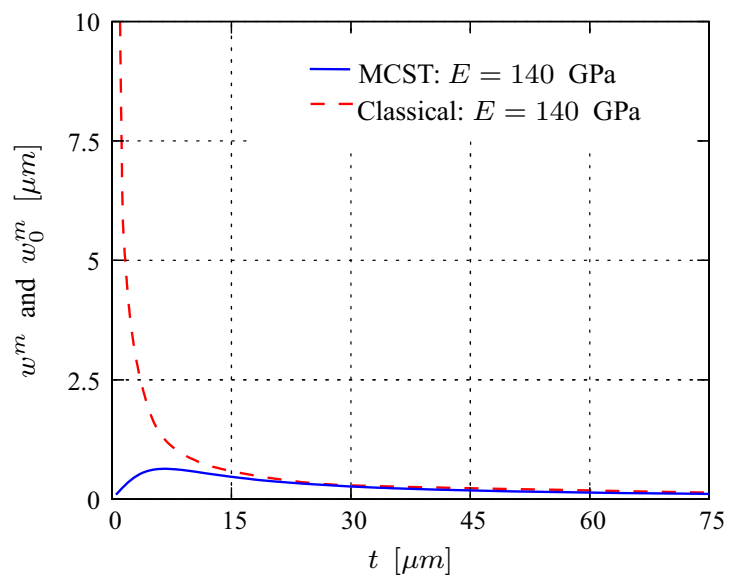

(f)

Fig. $10 w^{m}$ and $w_{0}^{m}$ for double cantilever beams with constant $t: b: L$ ratio of 1:5:20 for a MSGT versus classical theory and b MCST versus classical theory. $F=30 \mathrm{mN}$ 


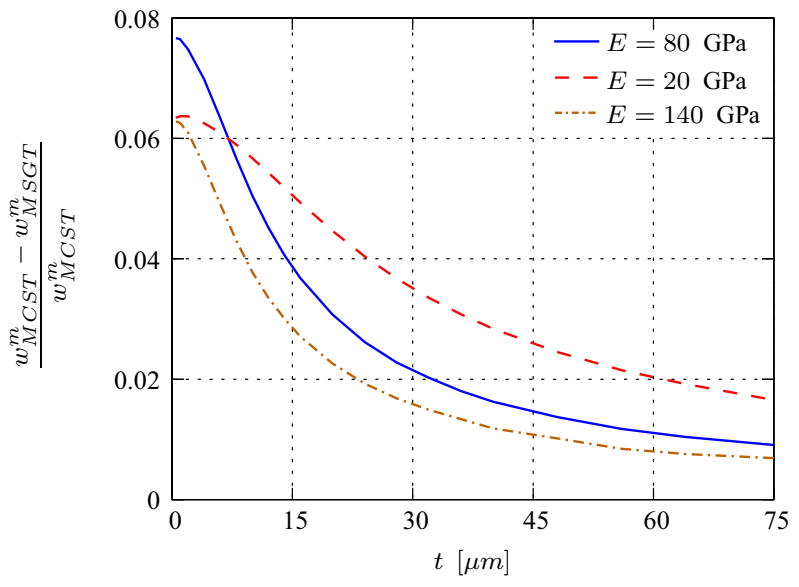

Fig. 11 Relative error for midpoint deflections based on elastic modulus and beam thickness. The length scale parameters are as discussed in Section 3.1, i.e. $l_{0}=3.60 \mu \mathrm{m}$ and $l_{2}=6.75 \mu \mathrm{m}$ for $E=80 \mathrm{GPa}, l_{0}=7.15 \mu \mathrm{m}$ and $l_{2}=13.50 \mu \mathrm{m}$ for $E=20$ $\mathrm{GPa}, l_{0}=2.70 \mu \mathrm{m}$ and $l_{2}=5.10 \mu \mathrm{m}$ for $E=140 \mathrm{GPa}$

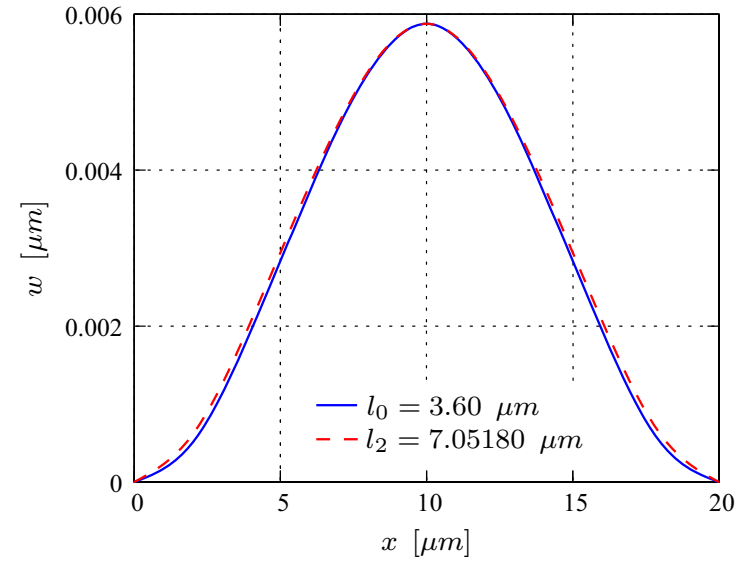

(a)

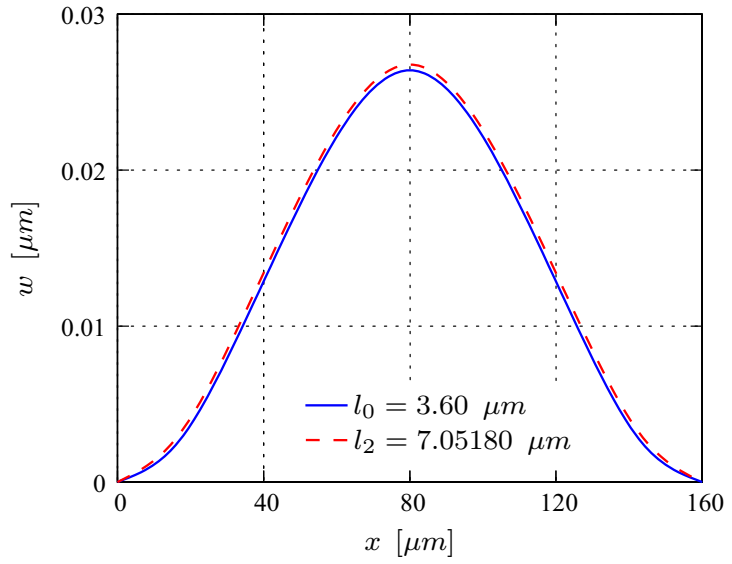

(b)

Fig. 12 Beam deflections for $E=80 \mathrm{GPa}, v=0.42$, aspect ratio $=1: 5: 20$, for corresponding $l_{0}$ for MSGT and $l_{2}$ for MCST. The beam dimensions are $\mathbf{a} t=1 \mu \mathrm{m}, b=5 \mu \mathrm{m}, L=20 \mu \mathrm{m}$, and $\mathbf{b} t=8 \mu \mathrm{m}, b=40 \mu \mathrm{m}, L=160 \mu \mathrm{m}$. $F=1 \mathrm{mN}$ for both cases

Publisher's Note Springer Nature remains neutral with regard to jurisdictional claims in published maps and institutional affiliations. 